worms. There is a larger proportion of animals with high calcium demand. Grain size has proved to be of more importance in determination of the community than depth. Carbonate input is also important. Below a certain concentration of shelled animals, above which a shell gravel may be maintained without difficulty, the bottom sediments may have a very low carbonate content with shelly material coming mainly from Foraminifera. Field observations suggest that where shell is at a premium, upon the death of its maker it would be promptly colonised as a substrate from which carbonate could be extracted by a new arrival or as a home to pagurids, often one of the commoner species in such conditions. They live in gastropod shells until these fall to bits (very few empty gastropod shells were found). Shell fragments disintegrate to about $2 \mathrm{~mm}$ and then completely collapse. The absence of carbonate in the sediments indicates that it is very rapidly recycled into living organisms. Some differences in community structure between facies 3 and facies 4 may be attributable not only to grain size but also to the amount of calcium available.

\title{
A multiple corer for taking virtually undisturbed samples from shelf, bathyal and abyssal sediments
}

\author{
P. R. O. Barnett, J. Watson and D. Connelly \\ Dunstaffnage Marine Research Laboratory, P.O. Box 3, Oban, Argyll PA34 4AD, \\ Scotland
}

Reliable samples are essential for accurate measurements of population densities, standing crops and energy flow. When sampling benthic meiofauna, it is necessary to sample the surface layer of the sea bed without disturbing or wafting it aside first before the sampler hits the bottom. It is well-known that most benthic samplers have serious deficiencies, yet the results obtained with them are frequently subjected to sophisticated techniques of statistical analysis. The problems of "bow-wave" effects when sampling the benthos have been emphasised by various authors for macrobenthos, meiobenthos and sedimentation rate and pollution studies.

Except for coring by divers, there is only one design of core sampler capable of taking a virtually undisturbed surface sediment sample; the Craib (1965) corer slowly lowers a plastic sampling tube into the sediment under the control of a hydraulic damper. Although this corer is very successful when used in sheltered inshore waters, there are considerable difficulties in obtaining samples from continental shelf and deep-sea sediments because valve-closing mechanisms are adversely affected by open sea conditions. Other alternatives for meiofaunal sampling include the use of benthic macrofaunal samplers (e.g. van Veen grabs, Reinek box corers) and subsequent subsampling by hand with small core tubes when the large sample has been recovered on deck. However, it has been shown that subsampling the van Veen grab will not give truly quantitative results; only subsampling in a box corer may be considered a quantitative method, although 
several subsamples must be taken so as to represent the whole area within the box because the sediment surface is somewhat disturbed. Box corers seldom produce a sample with an undisturbed surface layer and it is unlikely that, when subsampled, the distribution of the meiofauna in the surface layer of the recovered box-core sample will be the same as its distribution in the sea bed prior to sampling.

A new corer was designed to overcome these various problems, and a description is given of a multiple corer (Barnett et al. 1984), based on the principle of the Craib (1965) corer, which takes short samples of shelf, bathyal and abyssal sediments with virtually no disturbance. An array of up to twelve plastic core tubes is lowered slowly into the sediment by a hydraulic damper mounted on a supporting framework. Experience has shown the corer to be reliable and capable of taking cores with clear, overlying water with no disturbance of the sediment/water interface.

Photographs have confirmed the undisturbed nature of the sampling process in sand, mud and ooze sediments. This has been used to advantage to sample the seasonally-deposited phytoplankton debris that forms a flocculent detrital layer on the surface of deep-sea sediments at certain times of the year. The corer has proved to be a successful method of sampling for studies of the microbiology and meiobenthos of shelf and deep-sea sediments. A recent development has been its use in the measurement of oxygen uptake in sediment cores incubated virtually in situ at depths down to $5000 \mathrm{~m}$.

Barnett, P. R. O., Watson, J. \& Connelly, D. 1984. A multiple corer for taking virtually undisturbed samples from shelf, bathyal and abyssal sediments. Oceanologica Acta 7, 399408.

Craib, J. S. 1965. A sampler for taking short undisturbed marine cores. Journal du Conseil permanent international pour l'Exploration de la Mer 30, 34-39.

\section{Sampling deep-sea benthos}

\section{R. Harvey}

Dunstaffnage Marine Research Laboratory, P.O. Box 3, Oban, Argyll PA34 4AD, Scotland

The benthic sampling programme of the Scottish Marine Biological Association has investigated the distribution, abundance and biology of the animals living on the floor of the Rockall Trough at depths ranging from about 200 to $3000 \mathrm{~m}$. Repeated sampling at two fixed stations over a ten-year period, together with more widespread sampling, has created a unique time series of samples from the deep-sea bottom.

The low density of most benthic animals dictates the use of towed samplers in order to obtain sufficient specimens for detailed studies. A Woods Hole-pattern epibenthic sledge with a $1 \mathrm{~mm}$ mesh, decreasing to $0.5 \mathrm{~mm}$ meshes in the cod end extension, has been successfully used for the recovery of the small sized faunal taxa. The "megafauna" (those animals generally large enough to be seen in seabed photographs) has been sampled using a 3 m-wide Agassiz Trawl. Both trawls are normally towed on the bottom for one hour. Quantitative samples have been 